\title{
Spectral Analysis of Electroencephalography in Premature Newborn Infants: Normal Ranges
}

\author{
SURESH VICTOR, RICHARD E. APPLETON, MARGARET BEIRNE, ANTHONY G. MARSON, AND \\ A. MICHAEL WEINDLING \\ Department of Child Health [S.V., A.M.W.], University of Liverpool, Liverpool, United Kingdom; The \\ Roald Dahl EEG Unit [R.E.A., M.B.], Department of Neurology, Royal Liverpool Children's Hospital \\ NHS Trust (Alder Hey), Liverpool, United Kingdom; and Department of Neurological Science [A.G.M.], \\ University of Liverpool, Liverpool, United Kingdom
}

\begin{tabular}{|c|c|}
\hline \multicolumn{2}{|c|}{ ABSTRACT } \\
\hline $\begin{array}{l}\text { Continuous EEG monitoring has not been used widely in } \\
\text { neonatal intensive care, especially in the care of extremely } \\
\text { premature infants, probably in part because of a lack of a reliable } \\
\text { quantitative method. The purpose of this study was to quantify } \\
\text { the EEG of the very premature infants just after birth by using } \\
\text { spectral analysis and to describe the characteristics of the spectral } \\
\text { signal when infants were clinically stable. Digital EEG record- } \\
\text { ings were performed on } 53 \text { infants who were } \leq 30 \text { wk gestation } \\
\text { for } 75 \text { min each day during the first } 4 \text { d after birth. Artefact was } \\
\text { rejected manually after visual inspection of trace. The EEG was } \\
\text { analyzed by manual measurement of interburst interval and } \\
\text { automatically by spectral analysis using Fast Fourier Transfor- } \\
\text { mation. Spectral analysis generated the normal ranges of the } \\
\text { relative power of the } \delta \text { ( } 0.5-3.5 \mathrm{~Hz}), \theta \text { ( } 4-7.5 \mathrm{~Hz} \text { ), } \alpha \text { ( } 8-12.5 \\
\text { Hz), and } \beta \text { (13-30 Hz) frequency bands, spectral edge frequency, } \\
\text { and symmetry. The median (range) relative power of the } \delta \text { band }\end{array}$ & $\begin{array}{l}\text { increased significantly from } 68 \%(62-76 \%) \text { on day } 1 \text { to } 81 \% \\
(72-89 \%) \text { on day } 4(p=0.001) \text {. The interburst intervals became } \\
\text { progressively shorter between days } 1[14 \mathrm{~s}(10-25)] \text { and } 3 \text { [8s } \\
(6-12)] \text {; there were no significant differences between days } 3 \text { and } \\
4 \text {. The relative power of the } \delta \text { band seemed to be the most useful } \\
\text { and repeatable spectral measurement for continuous long-term } \\
\text { monitoring. However, automatic artefact rejection software } \\
\text { needs to be developed before continuous quantitative EEG mon- } \\
\text { itoring can be used in the neonatal intensive care environment. } \\
\text { (Pediatr Res 57: 336-341, 2005) }\end{array}$ \\
\hline
\end{tabular}

The hemodynamic status of extremely premature infants is particularly labile during the first days after birth. Intensive interventions for such infants are intended to maintain an adequate tissue oxygen supply, particularly to the brain. Because clinical management is aimed at preserving cerebral integrity in these infants, it would be helpful to have some form of continuous neuromonitoring to guide clinical interventions. EEG provides a useful, noninvasive technique for monitoring cerebral electrical activity, and advances in digital technology have made it possible to record high-quality EEG even in an electrically noisy intensive care environment and have done away with the necessity of using large amounts of recording paper. However, interpretation of the EEG is generally considered to be highly specialized, and this is at least one reason that

Received January 28, 2004; accepted August 16, 2004.

Correspondence: Suresh Victor, M.D., Neonatal Intensive Care Unit, Liverpool Women's Hospital, Crown Street, Liverpool L8 7SS, UK; e-mail: svictor@liverpool.ac.uk. Supported by the Newborn Appeal.

DOI: 10.1203/01.PDR.0000153868.77623.43 continuous EEG monitoring is not used widely in neonatal intensive care.

There are three major issues to be considered for the automatic and reliable analysis of the EEG signal of premature infants and for data to be presented in a manner that is useful to clinicians. First, the EEG of these infants consists predominantly of high-amplitude slow waves $(1,2)$. Bell et al. (3) showed that the relative power of slow waves with frequency $<1 \mathrm{~Hz}$ might be as high as $90 \%$ in infants at $28 \mathrm{wk}$ gestation. A recent study using DC EEG on infants between 34 and 37 wk gestation found that the spontaneous EEG activity of sleeping preterm infants consisted mainly of very slow, large-amplitude transients of $<0.5 \mathrm{~Hz}$ (2). The slow wave elements of the EEG signal are not suitably analyzed by commonly used monitoring techniques such as cerebral function monitor and cerebral function analyzing monitor, which use complex filters for frequencies $<2 \mathrm{~Hz}$ and $>15 \mathrm{~Hz}(4,5)$. The second problem is that the EEG acquired in intensive care environments is particularly prone to artefact and the reliable identification and removal of artefacts is essential. Finally, the normal EEG 
pattern of infants between 26 and $30 \mathrm{wk}$ gestation is markedly discontinuous and consists of long periods of quiescence, interspersed with bursts of electrical activity of high voltage and of mixed frequency $(1,6)$. It is therefore important that any automatic approach to EEG analysis be able to estimate the degree of discontinuity in the trace. With increasing gestational age, these interburst intervals decrease and the record becomes more continuous $(7,8)$. During the acute stages of brain injury in preterm infants, the EEG changes in continuity as well as in frequency and amplitude (9), and abnormal background EEG activity has been linked to adverse neurologic outcome (9-11). Because a prolonged interburst interval is the parameter of the preterm infant's EEG that has been most clearly found to be a marker of immaturity and impaired neurodevelopment, any automatically computed variable should be compared with the interburst interval.

Spectral analysis using Fast Fourier Transformation is a standard technique for quantifying EEG and other complex signals. However, little research has been performed using spectral analysis of the EEG in infants of $<30$ wk gestation, especially in the newborn period. Bell et al. (3) demonstrated a significant negative correlation between the absolute power of the signal below $1 \mathrm{~Hz}$ (the $\delta$ band) and gestational age in 60 infants between 29 and 42 wk gestation. The same authors also reported a significant positive correlation between the spectral edge frequency (the frequency below which $95 \%$ of the power resides) between 0.3 and $30 \mathrm{~Hz}$ and gestational age in 51 infants between 29 and 41 wk gestation (12). Others have studied sleep patterns and brain maturation using spectral energies in infants between 28 and 32 wk gestation (13-15).

Spectral analysis of the EEG was therefore performed during the first $4 \mathrm{~d}$ after birth in infants who were $\leq 30 \mathrm{wk}$ gestation. We aimed to describe normal ranges of spectral measurements, determine the test-retest repeatability of these measurements, and identify a useful and reliable measurement for the continuous monitoring of these very immature infants.

\section{METHODS}

Fifty-three infants who were $\leq 30$ wk gestation were studied on the first $4 \mathrm{~d}$ after birth at the neonatal intensive care unit, Liverpool Women's Hospital. Approval was obtained from the Local Research Ethics Committee. Informed parental consent was obtained.

Digital EEG with ECG recordings was performed at the bedside for $75 \mathrm{~min}$ every $24 \mathrm{~h}$ on each of the first $4 \mathrm{~d}$ after birth using the Micromed 19-channel system. For reduction of impedance, EEG abrasive skin preparation gel (Nuprep; D.O. Weaver and Co) was rubbed gently using cotton buds at measurement points on the scalp. Further reduction of impedance was achieved by using electrolyte gel (Redux gel; Parker Laboratories). Ten-twenty conductive EEG paste (D.O. Weaver and Co) was used for fixing miniature cupshaped silver-silver chloride electrodes. Disposable electrodes were used to reduce risk for infection. Electrodes were placed at Fp1, C3, O1, Fp2, C3, and O2 positions using the International 10-20 System (16). The reference electrode was placed at $\mathrm{Cz}$. The placement of an additional temporal lead proved technically difficult as hats that are used to stabilize endotracheal tubes restricted access to this area. Skin impedance of $<2 \mathrm{k} \Omega$ was maintained for all recordings. A sampling rate of $256 \mathrm{~Hz}$ was used for digitization, and the EEG was displayed on a computer screen. A high-pass filter of $0.3 \mathrm{~Hz}$, a low-pass filter of $70 \mathrm{~Hz}$, a notch filter of $50 \mathrm{~Hz}$, a base time of $10 \mathrm{~s}$, and a gain of 100 $\mu \mathrm{V}$ were used for recording the EEG.

Signal processing was carried out in the following order: spectral analysis, calculation of the relative power, absolute power and spectral edge frequency, and finally artefact removal. Each of the steps is described in more detail below. Spectral analysis was performed using the manufacturer's software
(Micromed). Six monopolar channels (Fp1, C3, O1, Fp2, C3, and O2) were used for the analysis. A basic assumption that is made when Fast Fourier Transformation is used for signal analysis is that the signal is constant for the period ( $2 \mathrm{~s}$ in this case) during which it is analyzed. The EEG trace was therefore segmented into multiple epochs of $2 \mathrm{~s}$ and then transformed. To improve the performance of spectral analysis, we used overlapping detrending and tapering. Overlapping (analysis of superimposed epochs) permitted the analysis of each trace element by locating it centrally within the epoch and was done by choosing consecutive epochs of $2 \mathrm{~s}$ with an overlap of $1 \mathrm{~s}$. Detrending (removal of any DC component) is a technique for flattening the baseline by suppression of very slow components. Tapering (windowing of the signal) reduces the phenomenon of spectral dispersion by multiplying the extreme component of the signal during the epoch by a constant, which is usually zero.

After Fast Fourier Transformation, the spectrum was subdivided into frequency bands: $\delta(0.5-3.5 \mathrm{~Hz}), \theta(4-7.5 \mathrm{~Hz}), \alpha(8-12.5 \mathrm{~Hz})$, and $\beta(13-30$ $\mathrm{Hz}$ ) bands. Three aspects of the transformed signal were calculated automatically: the absolute and the relative powers of each frequency band and the spectral edge frequency. The absolute power of a band is the integral of all of the power values within its frequency range and expressed in $\mu \mathrm{V}^{2}$. The relative power of a band is the ratio of the absolute power of that band to the total power of all bands and expressed as a percentage. Spectral edge frequency is the frequency that delimits $95 \%$ of the total spectral power between 0.5 and 30 $\mathrm{Hz}$ (12). Asymmetry was calculated as the ratio of the total absolute power of the recordings from the left side (Fp1, C3, and $\mathrm{O} 1)$ to the total absolute power of the recordings from the right side (Fp2, $\mathrm{C} 4$, and $\mathrm{O} 2)$.

The absolute and relative powers of each band and the spectral edge frequency were averaged for every $10 \mathrm{~s}$ and recorded in a spreadsheet. This resulted in 450 rows of data for the entire $75 \mathrm{~min}$ of EEG recording. Gross artefacts (signal with no identifiable normal EEG) were identified by eye using the unprocessed trace. More than $90 \%$ of artefacts were due to movement by the infant. Rows of 10-s epochs, corresponding to the time of artefacts, were then deleted from the spreadsheet. The intention was to analyze $60 \mathrm{~min}$ of artefact-free record. The first 360 remaining rows $(10 \mathrm{~s}$ each) of uncorrupted data were therefore used to calculate the absolute and relative powers of each band and the spectral edge frequency. The data showed a nonparametric distribution, and nonparametric descriptors were therefore used. The EEG recordings were divided into categories: those that were recorded when infants were in a clinically stable condition ("normal") and those that were recorded when the infants were unwell.

Data from each of the $4 \mathrm{~d}$ were analyzed separately. The following criteria were used to define normality: 1) base deficit of $<10 \mathrm{mM} / \mathrm{L}$ on the first blood gas analysis, 2) a normal appearance or small subependymal hemorrhages on cranial ultrasound scan performed soon after each EEG recording, 3) arterial carbon dioxide tensions between 30 and $50 \mathrm{~mm} \mathrm{Hg}$ midway during each recording, 4) mean arterial blood pressure $>30 \mathrm{~mm} \mathrm{Hg}$ throughout the recording, 5) normal blood glucose concentrations, 6) arterial oxygen tension $>40 \mathrm{~mm} \mathrm{Hg}, 7)$ mean airway pressure of $<10 \mathrm{~cm}$ water at the time of recording, and 8) no congenital abnormalities.

To determine whether the normal ranges of spectral measurements on each day needed to be analyzed further as subgroups, we then studied the effect on the relative powers of all frequency bands of 1$)$ the use of morphine (20 $\mu \mathrm{g}$ $\mathrm{kg}^{-1} \cdot \mathrm{h}^{-1}$ ), 2) the presence of subependymal hemorrhages, and 3) gestational age. The procedures were as follows. 1) Fourteen recordings were performed while infants were receiving morphine infusion on days 1 and 2, and only four recordings were performed during morphine infusion on days 3 and 4. MannWhitney tests compare the relative powers of all bands, 10 th centile $\left(\mathrm{P}_{10}\right), 50$ th centile $\left(\mathrm{P}_{50}\right)$, 90th centile $\left(\mathrm{P}_{90}\right)$, and percentage interburst intervals between infants who were on or off morphine infusion was performed. 2) Mann Whitney tests were used to compare the relative powers of all bands, $\mathrm{P}_{10}, \mathrm{P}_{50}$, $\mathrm{P}_{90}$, and percentage interburst intervals between infants with normal cranial ultrasound scans and infants with subependymal hemorrhages. 3) To determine the effect of gestational age, data from each day were divided into three gestational age groups (24-26 wk, 27-28 wk, and 29-30 wk). The relative power of each EEG band and the interburst intervals $\left(\mathrm{P}_{10}, \mathrm{P}_{50}, \mathrm{P}_{90}\right.$, and percentage) were compared between the three gestational bands using the Kruskal-Wallis test.

Test-retest assessment was performed to determine which spectral measurement gave the best repeatability in the presence of similar physiologic conditions. The EEG recorded on the third day after birth was repeated once after 18 to $24 \mathrm{~h}$ on 10 infants with a median gestational age of $27 \mathrm{wk}$ (range 25-28) and median birth weight of $1002 \mathrm{~g}$ (range 772-1320). The coefficient of repeatability was calculated by plotting the differences between pairs of measurements against the mean: twice the SD of the differences gave the coefficient of repeatability (17).

To determine the relationship between the spectral measurements and the interburst intervals, 50 EEG recordings on the first day after birth were analyzed. The infants in this group included those with intraventricular hem- 
orrhage and hemodynamic instability. The interburst interval was calculated manually. It was defined as a period between electrical bursts during which activities were $<30 \mu \mathrm{V}$ in all leads (18). Voltage was confirmed using the manufacturer's software (Micromed) when in doubt. Gross artefacts (activity with no identifiable normal EEG activity) were identified visually and excluded from the analysis. The $\mathrm{P}_{10}$, the median $\left(\mathrm{P}_{50}\right)$, the $\mathrm{P}_{90}$, and the percentage of time spent in electrical quiescence during the entire recording (percentage interburst interval) were calculated. $\mathrm{P}_{10}, \mathrm{P}_{50}, \mathrm{P}_{90}$, and percentage interburst intervals were then correlated with the relative power of each band and the spectral edge frequency.

\section{RESULTS}

The intention was to analyze $60 \mathrm{~min}$ of artefact-free record. This was achieved in $91 \%$ of recordings, and an additional 5\% were between 55 and $60 \mathrm{~min}$. The minimum duration of artefact-free recording used for analysis was $40 \mathrm{~min}$.

A total of 187 EEG recordings were made from 53 infants. There were 50 recordings on day 1,51 on day 2, 50 on day 3 , and 36 on day 4.

The normal ranges of spectral measurements of the EEG were obtained from 101 EEG recordings in 39 infants. Their median gestation was $27 \mathrm{wk}$ (range 24-30), and their median birth weight was $970 \mathrm{~g}$ (range 534-1522). Eighteen infants were male.

Eighty-six recordings were performed when infants were unwell. These 86 recordings were obtained from 40 infants (19 boys) with median gestational age of $26 \mathrm{wk}$ (range 23-30)) and median birth weight of $850 \mathrm{~g}$ (range 470-1522). The conditions of infants at the time of recording were as follows: 1) the base deficit was $>10 \mathrm{mM} / \mathrm{L}$ on the first blood gas (4 recordings), 2) there was intraventricular hemorrhage that extended beyond the germinal matrix ( 25 recordings), 3) arterial carbon dioxide levels were outside the preset range of $30-50 \mathrm{~mm} \mathrm{Hg}$ (24 recordings), 4) the mean blood pressure was $<30 \mathrm{~mm} \mathrm{Hg}$ (21 recordings), 5) blood glucose concentrations were low $(<2$ $\mathrm{mM} ; 2$ recordings), 6) arterial oxygen tension was $<40 \mathrm{~mm} \mathrm{Hg}$ ( 8 recordings), and 7) the mean airway pressure was $>10 \mathrm{~cm}$ $\mathrm{H}_{2} \mathrm{O}$ (2 recordings). The ranges of interburst intervals and spectral measurements were analyzed in this group as a separate category.

The results of test-retest assessment were as shown in Table 1. There was no relationship when the difference between pairs of measurements was plotted against the mean of the two measurements. The correlation between the relative power of

Table 1. Coefficient of repeatability of spectral parameters of EEG $(\mathrm{n}=10)$

\begin{tabular}{lccc}
\hline Spectral measure & $\begin{array}{c}\text { Mean } \pm \mathrm{SD} \\
(n=20)\end{array}$ & $\begin{array}{c}\text { Coefficient of } \\
\text { repeatability }\end{array}$ & $\begin{array}{c}\text { Coefficient of } \\
\text { repeatability } \\
\text { (\% of mean) }\end{array}$ \\
\hline AP of $\delta$ & $252 \pm 98 \mu \mathrm{V}$ & $272 \mu \mathrm{V}$ & $107 \%$ \\
AP of $\theta$ & $27 \pm 13 \mu \mathrm{V}$ & $35 \mu \mathrm{V}$ & $129 \%$ \\
AP of $\alpha$ & $13 \pm 10 \mu \mathrm{V}$ & $19 \mu \mathrm{V}$ & $146 \%$ \\
AP of $\beta$ & $17 \pm 9 \mu \mathrm{V}$ & $16 \mu \mathrm{V}$ & $94 \%$ \\
RP of $\delta$ & $78 \pm 5.4 \%$ & $8 \%$ & $10 \%$ \\
RP of $\theta$ & $9 \pm 2.2 \%$ & $3 \%$ & $33 \%$ \\
RP of $\alpha$ & $4 \pm 2.4 \%$ & $5 \%$ & $125 \%$ \\
RP of $\beta$ & $6 \pm 2.3 \%$ & $3 \%$ & $50 \%$ \\
SEF & $13 \pm 3.4 \mathrm{~Hz}$ & $5 \mathrm{~Hz}$ & $38 \%$ \\
Asymmetry & $1 \pm 0.2$ & 0 & $0 \%$ \\
\hline
\end{tabular}

$\mathrm{AP}$, absolute power; RP, relative power; SEF, spectral edge frequency. each frequency band and the spectral edge frequency with the interburst intervals $\left(\mathrm{P}_{10}, \mathrm{P}_{50}, \mathrm{P}_{90}\right.$, and percentage interburst interval) is shown in Table 2.

When EEG recordings from infants with normal head scans and from those with subependymal hemorrhages were compared, no statistically significant differences were found between the relative powers of each band and interburst intervals on any of the $4 \mathrm{~d}$. Comparing infants who were given morphine with those who were not, the $\mathrm{P}_{50}$ and percentage interburst intervals were higher for the infants who were on morphine, but the differences reached statistical significance only on day $2(p=0.007$ and $p=0.03$, respectively). The EEG of infants who were receiving morphine showed a lower relative power of the $\delta$ band than those who were not, but differences did not reach statistical significance. Only percentage interburst intervals were significantly lower with increased gestational age on day $3(p=0.03)$.

As subependymal hemorrhages, use of morphine and gestational age had no consistent statistically significant effect on the relative powers of all bands; data are presented for each day without any subgroups (Table 3). However, for comparison with other studies, data are presented according to gestational age groups in Table 4. As absolute power had high coefficients of repeatability, only the normal ranges $\left(\mathrm{P}_{10}-\mathrm{P}_{90}\right)$ of relative power of each band, spectral edge frequency, and asymmetry are shown in Tables 3 and 4 . The relative power of each band and the $\mathrm{P}_{10}, \mathrm{P}_{50}, \mathrm{P}_{90}$, and percentage interburst intervals of EEG recordings taken from infants at a time when they were unwell are described in Table 5.

The relative power of the $\delta$ band increased over the first $4 \mathrm{~d}$ after birth (Friedman test: $n=11 ; p=0.001$; Table 3). There was a significant increase in the relative power of the $\delta$ band between days 1 and 3 (Wilcoxon signed ranks test: $n=16, p$ $=0.002$ ) and between days 3 and 4 (Wilcoxon signed ranks test: $n=20, p=0.036$; Fig. 1). However, the differences between days 3 and 4 in the relative power of the $\delta$ band was not significant (Wilcoxon signed ranks test: $n=18 ; p=0.77$ ). The relative powers of the $\theta, \alpha$, and $\beta$ bands; spectral edge frequency; and interburst intervals showed significant decrease between days 1 and 2 and between days 2 and 3 but not between days 3 and 4 . The total power of the whole EEG signal and the absolute power of the $\delta$ frequency band showed an increase over the first $3 \mathrm{~d}$ after birth, and there was no change in these two measurements between days 3 and 4 . The absolute powers of the $\theta, \alpha$, and $\beta$ bands were unchanged over the $4 \mathrm{~d}$.

\section{DISCUSSION}

Normal ranges for the relative powers of each frequency band, the spectral edge frequency, and symmetry of the EEG during the first $4 \mathrm{~d}$ after birth in infants between 24 and 30 wk gestation are described in this article. The relative power of signal in the $\delta$ band showed the best coefficient of repeatability. Over the first $4 \mathrm{~d}$ after birth, there was a significant increase in the relative power of the $\delta$ band and significant decreases in the duration of the interburst intervals. 
Table 2. Pearson correlation (significance level) between spectral parameters and interburst intervals

\begin{tabular}{lcccc}
\hline & $\mathrm{P}_{10}$ IBI & $\mathrm{P}_{50}$ IBI & $\mathrm{P}_{90}$ IBI & $\%$ IBI \\
\hline RP of $\delta$ & $-0.2(0.44)$ & $-0.69(<0.001)$ & $-0.67(<0.001)$ & $-0.51(<0.001)$ \\
RP of $\theta$ & $0.0(0.99)$ & $0.32(0.024)$ & $0.28(0.05)$ & $0.16(0.28)$ \\
RP of $\alpha$ & $0.2(0.34)$ & $0.46(0.001)$ & $0.48(<0.001)$ & $0.4(0.004)$ \\
RP of $\beta$ & $0.2(0.35)$ & $0.38(0.006)$ & $0.40(0.004)$ & $0.38(0.007)$ \\
SEF & $0.26(0.23)$ & $0.36(0.01)$ & $0.42(0.003)$ & $0.42(0.002)$ \\
\hline
\end{tabular}

IBI, interburst interval.

Table 3. Normal ranges [median $\left(P_{10}-P_{90}\right)$ ] of spectral parameters and interburst intervals for the first 4 days after birth

\begin{tabular}{lcccc}
\hline & $\begin{array}{c}\text { Day } 1 \\
(n=23)\end{array}$ & $\begin{array}{c}\text { Day } 2 \\
(n=27)\end{array}$ & $\begin{array}{c}\text { Day } 3 \\
(n=27)\end{array}$ & $\begin{array}{c}\text { Day } 4 \\
n=24)\end{array}$ \\
\hline RP of $\delta(\%)$ & $68(62-76)$ & $75(65-82)$ & $79(70-87)$ & $9(7-89)$ \\
RP of $\theta(\%)$ & $12(10-16)$ & $10(8-16)$ & $4(2-12)$ & $4(2-7)$ \\
RP of $\alpha(\%)$ & $6(5-7)$ & $5(3-8)$ & $6(2-11)$ & $5(3-10)$ \\
RP of $\beta(\%)$ & $10(6-17)$ & $7(4-11)$ & $13(7-20)$ & $13(8-21)$ \\
SEF (Hz) & $19(13-24)$ & $15(12-20)$ & $1(0.8-1.2)$ & $1(0.8-1.2)$ \\
Asymmetry & $1(0.8-1.2)$ & $1(0.8-1.2)$ & $3(2-3)$ & $3(2-3)$ \\
P10 IBI (s) & $3(2-4)$ & $3(2-4)$ & $4(3-6)$ & $4(3-6)$ \\
Median IBI (s) & $6(4-8)$ & $5(4-9)$ & $8(6-12)$ & $9(4-13)$ \\
Po IBI (s) & $14(10-25)$ & $11(7-20)$ & $11(4-32)$ & $10(1-28)$ \\
\% IBI (\%) & $43(19-66)$ & $28(8-67)$ & & \\
\hline
\end{tabular}

Table 4. Normal ranges [median $\left(P_{10}-P_{90}\right)$ ] for spectral parameters and interburst intervals

\begin{tabular}{|c|c|c|c|c|c|c|c|c|c|c|}
\hline $\begin{array}{l}\text { Gestation } \\
\text { (weeks) }\end{array}$ & $\begin{array}{l}\text { Age } \\
\text { (d) }\end{array}$ & $\begin{array}{c}\mathrm{RP} \text { of } \delta \\
(\%)\end{array}$ & $\begin{array}{c}\mathrm{RP} \text { of } \theta \\
(\%)\end{array}$ & $\begin{array}{c}\mathrm{RP} \text { of } \alpha \\
(\%)\end{array}$ & $\begin{array}{c}\mathrm{RP} \text { of } \beta \\
(\%)\end{array}$ & $\begin{array}{l}\text { SEF } \\
(\mathrm{Hz})\end{array}$ & $\begin{array}{c}\mathrm{P}_{10} \mathrm{IBI} \\
(\mathrm{s})\end{array}$ & $\begin{array}{c}\mathrm{P}_{50} \mathrm{IBI} \\
(\mathrm{s})\end{array}$ & $\begin{array}{c}\mathrm{P}_{90} \text { IBI } \\
(\mathrm{s})\end{array}$ & $\begin{array}{c}\% \text { IBI } \\
(\%)\end{array}$ \\
\hline \multirow[t]{4}{*}{$24-26$} & $1(n=9)$ & $68(63-76)$ & $12(10-15)$ & $6(5-7)$ & $11(6-15)$ & $20(13-23)$ & $3(2-5)$ & $6(4-13)$ & $15(11-29)$ & $54(17-66)$ \\
\hline & $2(n=8)$ & $78(64-82)$ & $10(7-19)$ & $4(2-9)$ & $7(3-12)$ & $14(8-20)$ & $3(2-3)$ & $5(3-7)$ & $10(6-15)$ & $31(6-55)$ \\
\hline & $3(n=14)$ & $79(69-87)$ & $9(7-12)$ & $4(2-6)$ & $6(2-13)$ & $13(7-21)$ & $3(2-3)$ & $4(3-6)$ & $10(6-14)$ & $14(6-35)$ \\
\hline & $4(n=8)$ & $78(58-86)$ & $11(8-17)$ & $5(2-8)$ & $7(3-14)$ & $14(8-22)$ & $3(2-3)$ & $4(3-5)$ & $10(6-12)$ & $14(5-37)$ \\
\hline \multirow[t]{4}{*}{$27-28$} & $1(n=10)$ & $69(62-76)$ & $12(10-16)$ & $6(4-8)$ & $10(5-19)$ & $18(13-24)$ & $3(2-4)$ & $6(4-8)$ & $12(7-22)$ & $39(8-64)$ \\
\hline & $2(n=16)$ & $74(68-82)$ & $10(8-12)$ & $5(3-8)$ & $8(4-12)$ & $17(12-21)$ & $3(2-4)$ & $5(4-11)$ & $12(8-27)$ & $29(8-76)$ \\
\hline & $3(n=11)$ & $78(67-88)$ & $8(6-15)$ & $4(2-9)$ & $6(2-10)$ & $14(7-19)$ & $3(2-3)$ & $4(3-6)$ & $8(5-13)$ & $9(3-40)$ \\
\hline & $4(n=13)$ & $81(71-89)$ & $9(5-12)$ & $4(2-9)$ & $5(3-9)$ & $12(8-19)$ & $3(2-3)$ & $4(3-6)$ & $9(3-11)$ & $9(1-15)$ \\
\hline \multirow[t]{4}{*}{$29-30$} & $1(n=4)$ & $71(68-77)$ & $13(11-18)$ & $6(5-7)$ & $7(6-10)$ & $16(14-20)$ & $3(3-4)$ & $6(5-8)$ & $14(12-23)$ & $40(30-56)$ \\
\hline & $2(n=3)$ & $75(73-76)$ & $11(11-13)$ & $5(5-6)$ & $7(6-8)$ & $15(15-20)$ & $3(3-4)$ & $5(4-7)$ & $10(10-16)$ & $24(8-59)$ \\
\hline & $3(n=2)$ & $81(79-82)$ & $11(9-12)$ & $4(3-4)$ & $4(4-4)$ & $11(10-11)$ & $3(3-4)$ & $5(4-6)$ & $8(6-9)$ & $4(4-4)$ \\
\hline & $4(n=3)$ & $80(76-89)$ & $10(5-10)$ & $4(2-5)$ & $5(3-7)$ & $16(13-25)$ & $3(3-4)$ & $5(1-9)$ & $13(10-13)$ & $7(3-9)$ \\
\hline
\end{tabular}

Data are described according to gestational age.

Table 5. Median (range) of spectral parameters and interburst intervals for the first 4 days after birth of EEG recordings taken when infants were unwell

\begin{tabular}{lcccc}
\hline & Day $1(n=27)$ & Day $2(n=24)$ & Day 3 $(n=23)$ & Day $4(n=12)$ \\
\hline RP of $\delta(\%)$ & $68(20-78)$ & $72(37-85)$ & $77(64-89)$ & $78(70-86)$ \\
RP of $\theta(\%)$ & $13(8-17)$ & $11(7-18)$ & $9(5-15)$ & $10(6-15)$ \\
RP of $\alpha(\%)$ & $6(4-14)$ & $6(3-11)$ & $4(2-9)$ & $4(3-7)$ \\
RP of $\beta(\%)$ & $12(4-37)$ & $8(4-41)$ & $7(3-21)$ & $6(3-13)$ \\
SEF (Hz) & $21(11-28)$ & $16(7-24)$ & $15(7-20)$ & $13(9-18)$ \\
Asymmetry & $1(0.6-1.7)$ & $1(0.8-1.5)$ & $1(0.7-1.6)$ & $1(0.8-1.2)$ \\
P $_{10}$ IBI (s) & $3(2-4)$ & $3(2-4)$ & $3(2-3)$ & $3(2-3)$ \\
Median IBI (s) & $7(0-21)$ & $5(3-10)$ & $5(2-8)$ & $4(4-8)$ \\
P $_{90}$ IBI (s) & $18(0-51)$ & $13(4-31)$ & $10(4-16)$ & $9(7-16)$ \\
IBI $(\%)$ & $58(0-84)$ & $39(2-72)$ & $23(1-59)$ & $13(6-52)$ \\
\hline
\end{tabular}

The EEG signal is susceptible to artefact, which automatic processing did not detect and which had to be rejected manually after inspection. In $91 \%$ of recordings, an extra 15 min of recording was required to provide $60 \mathrm{~min}$ of artefact-free EEG. This suggests that an artefact rejection program needs to be developed before this technology for the automatic analysis of the EEG of preterm infants can be accepted on a neonatal intensive care unit.
One of the purposes of this study was to identify the single most useful spectral parameter for continuous EEG monitoring. This study has shown that changes in continuity correlated with changes in the relative power of the $\delta$ band but not with other measurements of the EEG spectrum. Also, the relative power of the $\delta$ band had the best repeatability. One of the basic assumptions of Fast Fourier Transformation is that the EEG signal is stationary during a window of 2 s. However, a 


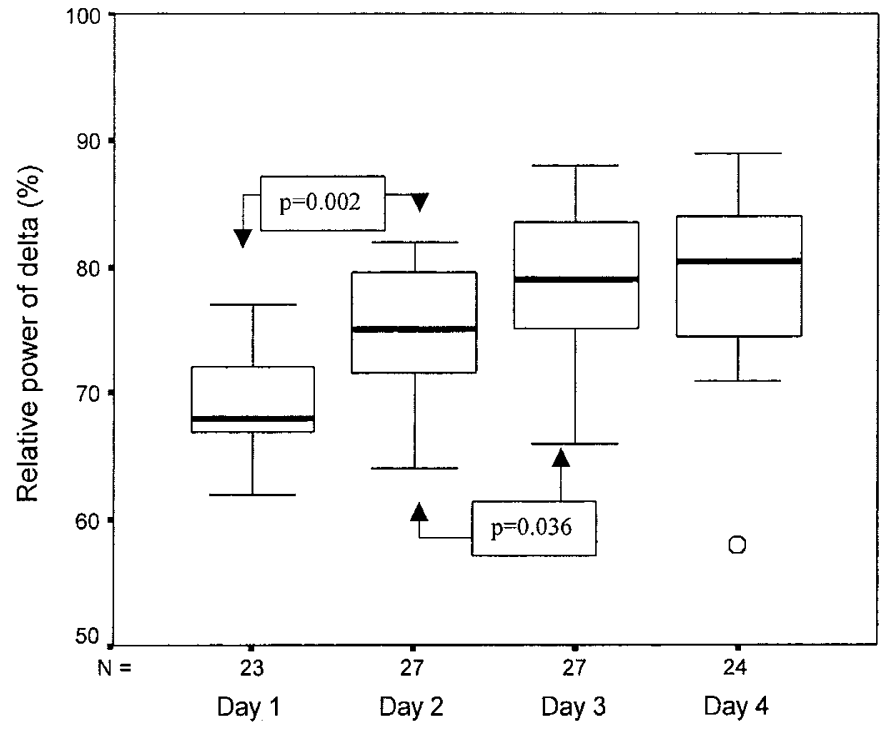

Figure 1. Boxplot showing changes in the relative power of the $\delta$ band over the first $4 \mathrm{~d}$ after birth.

stationary signal between 13 and $30 \mathrm{~Hz}$ was not seen for these higher frequencies over the whole 2-s window. This suggests that spectral analysis may not be an appropriate method for analyzing higher EEG frequencies. The observation may also explain why the relative power of the $\delta$ band seemed to be a potentially useful measurement for continuous EEG monitoring in premature infants when the signal is made up predominantly of lower frequencies.

Normal ranges of interburst intervals from day 1 are described and compared with other studies in Table 6. There were some notable differences. In particular, in contrast to the mean interburst intervals and maximum interburst intervals reported by other authors, we report the $\mathrm{P}_{10}, \mathrm{P}_{50}$, and $\mathrm{P}_{90}$ interburst intervals. It seemed appropriate to describe the interburst in- terval data using nonparametric descriptors because the data were not normally distributed and there was a marked skew toward the higher end. As the maximum interburst interval is the most commonly quoted (Table 6 ) and has been associated with adverse neurodevelopmental outcome $(9-11)$, the $\mathrm{P}_{90}$ interburst interval may be the best measurement of interburst interval to use.

The interburst intervals described in this study are different from those described by others (Table 6). Only Hahn et al. (19) reported shorter interburst intervals, which they defined using highly restrictive criteria (no cerebral activity $>15 \mu \mathrm{V}$ in any of the channels). Since then, others have used less restrictive criteria of no cerebral electrical activity $>30 \mu \mathrm{V}(8,18)$, a method adopted in the present study. Other groups have reported longer interburst intervals $(7,8,10,18,20,21)$. Anderson et al. (20) included infants with abnormal outcome (three infants died), and cranial ultrasound examinations were not performed routinely. Benda et al. (10) and Biagioni et al. (18) included infants with large intraventricular hemorrhages and those with ventricular dilation on the basis of normal neurologic outcome at $3 \mathrm{y}$ and $18 \mathrm{mo}$, respectively. However, the EEGs of these children were unlikely to have been normal at the time of recording. The studies by Eyre et al. (7) and Connell et al. (21) examined EEG recordings during the first $4 \mathrm{~d}$ after birth, but both used only two-channel EEG (F3-P3, F4-P4) for the convenience of prolonged recordings. The longer interburst intervals observed by them might have been because activity in other regions of the brain was missed. Eyre et al. (7) also defined interburst intervals as the time interval between the onset of suppressed activity and onset of next burst; they did not specify voltage criteria. Connell et al. (8) scored the four most discontinuous epochs (15 min each), whereas Hayakawa et al. (21) scored only those intervals that were $>5$ s long.

Table 6. Progression of interburst intervals across gestational age as reported by other studies

\begin{tabular}{|c|c|c|c|c|c|}
\hline Study & $\begin{array}{l}\text { Gestation } \\
\text { (wk) }\end{array}$ & $n$ & $\begin{array}{l}\text { Mean IBI } \\
\text { (s) }\end{array}$ & $\begin{array}{l}\text { Maximum IBI } \\
\text { (s) }\end{array}$ & $\%$ IBI \\
\hline Hayakawa et al (8) & $25-26$ & 6 & $13 \quad(10-16)$ & $44(19-76)$ & $48(19-49)$ \\
\hline Benda et al (10)* & $25-26$ & 4 & & $22(11-34)$ & \\
\hline Benda et al (10)* & $27-28$ & 19 & & $9(4-31)$ & \\
\hline Benda et al (10)* & $29-30$ & 17 & & $8(4-17)$ & \\
\hline Anderson et al (20) & $27-28$ & 8 & $12(8-16)$ & $48(15-88)$ & $62(11-90)$ \\
\hline Anderson et al (20) & $29-30$ & 11 & $9 \quad(5-14)$ & $36(16-57)$ & $53(0-87)$ \\
\hline Eyre et al $(7) \dagger$ & 26 & & $26(18-34)$ & & \\
\hline Eyre et al $(7) \dagger$ & 28 & & $26 \quad(20-33)$ & & \\
\hline Eyre et al $(7) \dagger$ & 29 & & $22(18-28)$ & & \\
\hline Hahn et al (19)† & $26-27$ & 5 & $5.4(5-6)$ & $10(7-19)$ & \\
\hline Hahn et al (19)† & $28-29$ & 15 & $5.6(5-6)$ & $10(4-32)$ & \\
\hline Biagioni et al (18) $\ddagger$ & $27-28$ & 7 & & $31 \pm 14$ & \\
\hline Biagioni et al $(18) \ddagger$ & $29-30$ & 10 & & $30 \pm 21$ & \\
\hline Connell et al (21)† & $26-27$ & 3 & $14 \quad(9-17)$ & $60(35-80)$ & $30(20-50)$ \\
\hline Connell et al $(21) \dagger$ & $28-29$ & 4 & $12(8-16)$ & $50(25-70)$ & $20(10-40)$ \\
\hline Present study* & $26-27$ & 9 & $6 \quad(4-13)$ & $15(11-29)$ & $54(17-66)$ \\
\hline Present study* & $27-28$ & 10 & $6 \quad(4-8)$ & $14(7-22)$ & $39(8-64)$ \\
\hline Present study* & $29-30$ & 3 & $5 \quad(5-8)$ & $12(11-23)$ & $19(18-56)$ \\
\hline
\end{tabular}

Mean (ranges) are reported.

* Median $\left(\mathrm{P}_{10}-\mathrm{P}_{90}\right)$ calculated.

$\dagger$ Figures and not numerical data reported. Data extracted from figures showing mean (SD).

$\ddagger$ Mean \pm 1 SD reported. 
This study has not shown a relationship between gestation and changes in the spectral measurements and interburst intervals. This is in contrast to the findings reported by others, who have described a negative relationship between gestational age and interburst intervals $(7,21)$. However, the present study comprised infants of a relatively narrow gestational age range, in contrast to other studies, which included infants of a wider range of gestational ages $(26-42 \mathrm{wk})(7,21)$. When a narrower gestational age range of 24 to $28 \mathrm{wk}$ is examined, there is very little difference in the ranges of normal interburst intervals reported by Eyre et al. (7), Hahn et al. (18), and Biagioni et al. (19). As shown in Table 6, at $\sim 30 \mathrm{wk}$ gestation, the interburst intervals begin to shorten until the EEG becomes continuous at term. This would be consistent with cortical growth and maturation as described, for example, by Hüppi et al. (22-24), who used magnetic resonance imaging to demonstrate a 4-fold increase in gray matter volume between 30 and 40 wk gestation, much of which may be due to dendritic and axonal branching.

Whereas other studies have reported a gradual decrease in the absolute power of the $\delta$ band and the amplitude of the $\delta$ waves with increase in gestational age (3), the present study found an increase in the absolute and relative power of the $\delta$ band over the first $3 \mathrm{~d}$ after birth only. The increase in slow wave activity over the first $3 \mathrm{~d}$ without further increase between days 3 and 4 was striking. One explanation is that it was due to increased cerebral oxygen delivery over the first $3 \mathrm{~d}$ after birth, in keeping with several reports of an increase in cerebral blood flow during this period $(25,26)$. A second possibility is that the observed EEG changes may be related to the withdrawal of morphine as a sedative, although the effect of morphine on the relative power of the $\delta$ band and on the interburst interval was not statistically significant. Finally, the changes were much too rapid to suggest maturation of the premature brain as the cause for the increase in $\delta$ activity.

In conclusion, normal ranges of spectral measurements have been described in the EEG of infants between 24 to $30 \mathrm{wk}$ gestation over the first $4 \mathrm{~d}$ after birth. Significant EEG changes occur during the first $3 \mathrm{~d}$ after birth. If Fast Fourier Transformation is to be used, then the relative power of the $\delta$ band seems to be the most useful and repeatable spectral measurement for continuous long-term monitoring. However, automatic artefact rejection software needs to be developed before continuous quantitative EEG monitoring can be used in the neonatal intensive care environment.

\section{REFERENCES}

1. Scher MS 1999 Electroencephalography of the newborn: normal and abnormal features. In: Niedermeyer E, Da Silva FL (eds) Electroencephalography: Basic
Principles, Clinical Applications, and Related Fields. Lippincott Williams \& Wilkins, Baltimore, pp 896-946

2. Vanhatalo S, Tallgren P, Andersson S, Sainio K, Voipio J, Kaila K 2002 DC-EEG discloses prominent, very slow activity patterns during sleep in preterm infants. Clin Neurophysiol 113:1822-1825

3. Bell AH, McClure BG, McCullagh PJ, McClelland RJ 1991 A variation in power spectral analysis of the EEG with gestational age. J Clin Neurophysiol 8:312-319

4. Maynard D, Prior PF, Scott DF 1969 Device for continuous monitoring of cerebral activity in resuscitated patients. BMJ 4:545-546

5. Maynard DE 1979 Development of the CFM: the cerebral function analysing monitor (CFAM). Ann Anesthesiol Fr 20:253-255

6. Lamblin MD, Andre M, Challamel MJ, Curzi-Dascalova L, d'Allest DM, De Giovanni E, Mousalli-Salefranque F, Navelet Y, Plouin P, Redvanyi-Bouvet MF, Samson-Dollfus D, Vecchierini-Blineau MF 1999 Electroencephalograph of the premature and term newborn. Maturational aspects and glossary. Neurophysiol Clin 29:123-219

7. Eyre JA, Nanei S, Wilkinson AR 1988 Quantification of changes in normal neonatal EEGs with gestation from continuous five-day recordings. Dev Med Child Neurol 30:599-607

8. Hayakawa M, Okumura A, Hayakawa F, Watanabe K, Ohshiro M, Kato Y, Takahashi R, Tauchi N 2001 Background electroencephalographic (EEG) activities of very preterm infants born at less than 27 weeks gestation: a study on the degree of continuity. Arch Dis Child Fetal Neonatal Ed 84:F163-F167

9. Watanabe K, Hayakawa F, Okumura A 1999 Neonatal EEG: a powerful tool in the assessment of brain damage in preterm infants. Brain Dev 21:361-372

10. Benda GI, Engel RC, Zhang YP 1989 Prolonged inactive phases during the discontinuous pattern of prematurity in the electroencephalogram of very-low-birthweight infants. Electroencephalogr Clin Neurophysiol 72:189-197

11. Marret S, Parain D, Menard JF, Blanc T, Devaux AM, Ensel P, Fessard C, SamsonDollfus D 1997 Prognostic value of neonatal electroencephalography in premature newborns less than 33 weeks of gestational age. Electroencephalogr Clin Neurophysiol 102:178-185

12. Bell AH, McClure BG, McCullagh PJ, McClelland RJ 1991 Spectral edge frequency of the EEG in healthy neonates and variation with behavioural state. Biol Neonate 60:69-74

13. Scher MS, Sun M, Steppe DA, Guthrie RD, Sclabassi RJ 1994 Comparisons of EEG spectral and correlation measures between healthy term and preterm infants. Pediatr Neurol 10:104-108

14. Scher MS, Steppe DA, Banks DL, Guthrie RD, Sclabassi RJ 1995 Maturational trends of EEG-sleep measures in the healthy preterm neonate. Pediatr Neurol 12:314-322

15. Scher MS, Dokianakis SG, Sun M, Steppe DA, Guthrie RD, Sclabassi RJ 1996 Computer classification of sleep in preterm and full-term neonates at similar postconceptional term ages. Sleep 19:18-25

16. Jasper HH 1958 The Ten-twenty electrode system of the International Federation. Electroencephalogr Clin Neurophysiol 10:371-375

17. Bland JM, Altman DG 1986 Statistical methods for assessing agreement between two methods of clinical measurement. Lancet 1:307-310

18. Biagioni E, Bartalena L, Boldrini A, Cioni G, Giancola S, Ipata AE 1994 Background EEG activity in preterm infants: correlation of outcome with selected maturational features. Electroencephalogr Clin Neurophysiol 91:154-162

19. Hahn JS, Monyer H, Tharp BR 1989 Interburst interval measurements in the EEGs of premature infants with normal neurological outcome. Electroencephalogr Clin Neurophysiol 73:410-418

20. Anderson CM, Torres F, Faoro A 1985 The EEG of the early premature. Electroencephalogr Clin Neurophysiol 60:95-105

21. Connell JA, Oozeer R, Dubowitz V 1987 Continuous 4-channel EEG monitoring: a guide to interpretation, with normal values, in preterm infants. Neuropediatrics 18:138-145

22. Huppi PS, Warfield S, Kikinis R, Barnes PD, Zientara GP, Jolesz FA, Tsuji MK, Volpe JJ 1998 Quantitative magnetic resonance imaging of brain development in premature and mature newborns. Ann Neurol 43:224-235

23. Kostovic I, Judas M 2002 Correlation between the sequential ingrowth of afferents and transient patterns of cortical lamination in preterm infants. Anat Rec 267:1-6

24. Rakic P 1988 Specification of cerebral cortical areas. Science 241:170-176

25. Meek JH, Tyszczuk L, Elwell CE, Wyatt JS 1998 Cerebral blood flow increases over the first three days of life in extremely preterm neonates. Arch Dis Child Fetal Neonatal Ed 78:F33-F37

26. Naulaers G, Morren G, Van Huffel S, Casaer P, Devlieger H 2002 Cerebral tissue oxygenation index in very premature infants. Arch Dis Child Fetal Neonatal Ed 87:F189-F192 